\title{
Optimal Inventory Control of Obsolete Products with Price-Dependent Demand
}

\author{
Hassan Zamani Bajegani and Mohammad Reza Gholamian* \\ School of Industrial Engineering, Iran University of Science and Technology, Tehran, Iran \\ *Corresponding Author: Gholamian@iust.ac.ir
}

Submitted: $12 / 06 / 2019$

Revised: $\quad 16 / 12 / 2019$

Accepted: 15/01/2020

\begin{abstract}
Since pricing is recognized as one of the most important tools for profit optimization, price competition is one of the major issues facing companies. Determining the appropriate inventory control policy and optimal selling price of various products is a major subject of scientific and industrial research in recent years. On the other hand, today, some of the products on the market have the potential to become obsolete, which means that their demand is reduced at once with the development of new technology. Therefore, determining the optimal price and inventory policies for these types of products is very crucial. In this research, an inventory control model for a retailer is formulated to optimize the inventory and pricing decisions for profit maximization simultaneously. According to the problem assumptions, demand is price-dependent, the time that product becomes obsolete has an exponential distribution, the type of product obsolescence is also sudden, and the retailer determines the optimum price and order quantity of replenishment. The proposed model has a nonlinear profit function, in which the partial derivatives of the objective function are used to reach the optimal value. Finally, the effects of various parameters such as the speed of obsolescence, the holding cost of each item unit, the cost of selling obsolete items, and the purchasing price were studied on the total profit. For this purpose, a numerical example is solved along with a sensitivity analysis to evaluate the validity of the model and investigate the effect of parameters on the optimal solution. The key achievement of this study was the development of a new model and providing a solution to determine the optimal values of product sales price and retailer order quantity with maximum profit.
\end{abstract}

Keywords: Inventory Control; Pricing; Obsolescence; Price-Dependent Demand.

\section{INTRODUCTION}

Determining the optimal price of the products has been a key issue for corporate decisions at all times. Pricing is one of the essential elements of a marketing plan and decisive aspects of inventory control modeling. Also, pricing has an important role in determining the amount of capital and income of the organizations, concerning costs of production, distribution, sales, advertising, and product bundling. For this reason, the topic of optimal pricing has attracted the attention of many researchers in the research sources.

If the product is perishable, the importance of pricing increases because the demand for these items can be better managed by offering the appropriate pricing solutions and preventing the waste of capital due to spoliation or deterioration. It should be noted that, in general, perishability is defined as the decay, damage, dryness, spoilage, evaporation, deterioration, obsolescence, loss of utility, or loss of marginal value of a product that results in decreasing 
usefulness compared to the fresh one (Wee, 1993). Also, pricing is one of the most important factors influencing the level and type of demand in a supply chain (Yang, 2004). Hence, pricing-inventory models of perishable products have been the focus of many researchers over the past two decades.

On the other hand, in recent years, researchers in the field of inventory control have increasingly examined product lifetime. Product lifetime is generally affected by the technological changes. Many products in real markets, especially in high-tech industries, are becoming outdated with emerging new technologies after a while. In addition, with the advent of new technology, demand for the previous products decreases. The correct decision-making about ordering the quantity of these products and their selling price during the boom of these products is the main issue of the industries and organizations. A prominent example of these type of products is the electrical appliance, including laptops and mobile phones. In this category of products, the manufacturers launch new models every few months and easily capture the market share of previous models and stop their production and ordering (Goyal and Giri 2001). Therefore, pricing should be considered along with inventory control issues to better manage demand and create optimal inventory policies (Abad 2003).

These types of the products are known as obsolescence products and unfortunately, despite the wide range of scientific researches on other types of perishable products (i.e., deterioration, decay, and so on), this type of perishable products has not received much attention on the part of scientific research. Specially, few researchers have investigated on pricing for obsolete items. Since price and order quantity are closely interrelated with each other, this study attempts to provide an appropriate answer to the question of determining the optimal price and quantity of the ordered items with a rapid obsolescence rate. Items with rapid obsolescence rate are the products whose demand declines rapidly and tends to zero (Raafat, 1991).

In this paper, a pricing and inventory control model is used simultaneously for the products that are encountering with obsolescence at the retailer level. The purpose of this model is to find the optimal retailer pricing value optimal ordering quantity, to maximize the total retailer's profit. To this end, a mathematical optimization approach was used for modeling these issues based on a case study from the real world, and then the solution methods have been discussed.

The rest of the paper is organized as follows. First, in the next section, the literature of the topic is reviewed. Assumptions and notations are introduced in section 3, and then the mathematical model is presented in section 4. Numerical results and sensitivity analysis are shown in sections 5 and 6, and finally, the paper is concluded with summary and future trends in section 7.

\section{LITERATURE REVIEW}

The studies on inventory control by early 1960 show that all products are assumed as infinite lifetime and invariable property. However, many products including decay products such as alcohol and naphthalene, perishable products such as fruits and vegetables, and obsolete products such as high-tech and fashion products may change over time. While perishable and decay products are changed by evaporation, dryness, spoilage, damage, and so on, the obsolete products are outmoded. The main difference between these two categories is the necessity of taking the product lifetime into account in obsolescence cases. Unfortunately, there are limited studies on this category compared with two other categories. As mentioned, since the price and product lifetime are closely related, this study tries to answer the question of how the price and order quantity for the products with future obsolescence are determined, especially, whenever the high-tech products with less lifetime are considered.

As the first study in this category, Cobbaert and Oudheusden (1996) proposed a model to control products with the risk of fast and unexpected obsolescence. They have examined the model with fixed and variable obsolescence 
rates in two cases, with and without shortage. Joglekar and Lee (1993) suggested a model for obsolete products with exponential distribution. Besides, they have studied obsolete products in terms of price to maximize the retail profit (Joglekar and Lee, 1996). They presented an inventory control model by which the demand is a decreasing function associated with the increasing price and time, but the sudden stop of demand occurs after a time. Song and Lau (2004) suggested a model to control the obsolete products in terms of periodic probability demand, which is developed based on the dynamic programming approach. Wang and Tung (2011) solved an inventory control model considering the amount of demand during the product lifetime as a function of population growth and discount. Delft and Vial (1996) investigated the control of obsolete products with a short lifetime and calculated the optimal order quantity by considering the discount rate. Finally, Persona et al. (2005) proposed the consignment stock policy for obsolete products.

On the other hand, there are many studies about pricing of deteriorating products. Avinadav et al. (2013) determined the optimal price of deteriorating products concerning demand dependency on time and price. In this research, the product lifetime was fixed, and the demand was considered as a reduced binomial distribution function related to price. In addition, Avinadav et al. (2014) implemented the process of pricing and inventory control by considering the dependency of demand on product lifetime. They have developed the demand function in three forms of exponential, linear, and geometrical functions.

Dye (2012) proposed a model considering delay in payment and time/price-dependent demand, in which profit maximization was achieved by determining the optimal price and order quantity. Ghoreishi et al. (2013) have presented a model to maximize profit based on the selling price and optimal order quantity. They have examined time and pricedependent demand and modeled the inventory in terms of inflation and partial backlogging. Maihami et al. (2014) have examined deteriorating products based on the promotion activities. Rabbani et al. (2015) presented a model for the dynamic pricing of deteriorating products. Zhang et al. (2015) suggested a model for the dynamic pricing of noninstantaneous deteriorating products with inventory-dependent demand.

Sato (2015) suggested a model to control perishable products in terms of dynamic pricing, in which customers can postpone the purchasing decisions. Hong and Lee (2012) presented a pricing model by which the demand is dependent on price, guaranteed lead time, and lateness penalty offered by the supplier to customers. Alfares et al. (2016) have studied pricing and inventory control about demand, purchasing, and holding costs such that the purchasing cost depends on the quantity of demand and the holding cost depends on time. The discount was also considered based on the quantity of the ordered products.

Nakade and Ikeuchi (2016) proposed an optimal ordering and pricing model for fresh foods at a discounted price. Feng et al. (2017) presented a model for the inventory control and pricing of perishable products by which the demand is dependent on price, freshness, and inventory. In this work, the assumption of the zero levels of the final inventory is violated, and three variables including pricing, length of cycle time, and final inventory level were considered in profit maximization objective function. Li et al. (2017) examined the inventory control and pricing of perishable products among retailers. They used the policy of delay in payment to suppliers and delays in receiving money from customers. Meanwhile, inflation was also considered in this model. They assumed greater demand for fresh products with a higher lifetime. Therefore, demand is dependent on price and freshness. Maihami et al. (2017) presented a model for the inventory control and pricing of noninstantaneous deteriorating products considering the two-level delay in payment. The model is developed under partial backlogging shortage and based on probabilistic demand in three uniform, triangular and beta distribution functions. Soni and Chauhan (2018) provided an integrated inventory and pricing model for deteriorating products considering time proportional deterioration, partial backlogging, stochastic demand, and advertising. Finally, Taleizadeh et al. (2016) have investigated an EPQ model of lot sizing and pricing considering the price-dependent demand in a closed-loop supply chain. The reviews are summarized in Table 1. 
According to Table 1, the studies show that, unlike the deteriorating products, a few articles have presented the pricing of obsolete products. For this reason, the study of this issue in the field of obsolete products is of great interest. After sudden obsolescence, demand at once drops to zero, the optimal ordering and pricing play a decisive role in the profitability of the retailer, and hence in this research, it is attempted to determine the optimal amount of the order based on price-dependent demand, which has not been studied in obsolete products so far.

As a recent study, Mahmoodi (2019) introduced an inventory control model for replaceable deteriorating items with a linear price-dependent demand for duopoly retailers. Replaceable items are the items that are sold under different brands. The modeling was performed by two retailers and with and without considering shortage. Then, the model was solved using the game theory approach.

Chen (2019) proposed a hybrid model of pricing and inventory control, for perishable items in terms of the impact of promotional activities between one manufacturer and several retailers. To illustrate the advantages and disadvantages of an integrated supply chain, the model was offered and solved in the form of vendor management inventory (VMI) under "just-in-time" replenishment policy and was compared by a decentralized model as a benchmark approach. Azadi et al. (2019) proposed a hybrid of pricing and inventory optimization in the form of two-stage stochastic model for perishable items. In this model, the selected supplier replenishment plan is specified under a periodic-review inventory control policy and considering nonstationary demand and supply. 


\begin{tabular}{|c|c|c|c|c|c|c|c|c|c|c|c|c|c|}
\hline \multirow{3}{*}{ 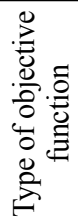 } & \multicolumn{2}{|l|}{$\begin{array}{c}\text { Order } \\
\text { Quantity }\end{array}$} & $*$ & $*$ & $*$ & $*$ & $*$ & $*$ & $*$ & & & $*$ & $*$ \\
\hline & \multicolumn{2}{|c|}{ Cycle Time } & & & $*$ & & & & $*$ & $*$ & & * & $*$ \\
\hline & \multicolumn{2}{|l|}{ Pricing } & & & & & & & & $*$ & $*$ & * & $*$ \\
\hline \multirow{19}{*}{ 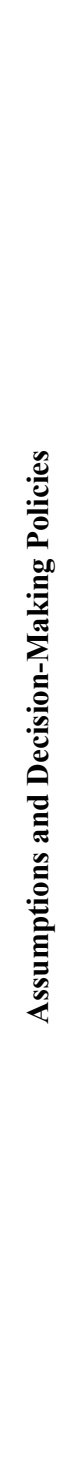 } & \multicolumn{2}{|l|}{ Inflation } & & & & & & & & & & & $*$ \\
\hline & \multicolumn{2}{|l|}{$\begin{array}{l}\text { Delay in } \\
\text { Payment }\end{array}$} & & & & & & & & $*$ & & & $*$ \\
\hline & \multirow{2}{*}{ 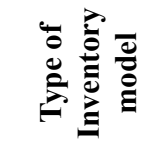 } & EPQ & & & & & & & & & & & \\
\hline & & EOQ & $*$ & $*$ & $*$ & $*$ & $*$ & $*$ & $*$ & $*$ & $*$ & $*$ & $*$ \\
\hline & \multirow{3}{*}{ 造 } & Multi & & & & & & & & & & & \\
\hline & & Two & & & & & & & & & & & \\
\hline & & One & $*$ & $*$ & $*$ & $*$ & $*$ & $*$ & $*$ & $*$ & $*$ & $*$ & $*$ \\
\hline & \multirow{2}{*}{ 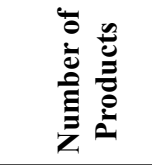 } & Multi & & & & & & & & & & & \\
\hline & & One & $*$ & $*$ & $*$ & $*$ & $*$ & $*$ & $*$ & $*$ & $*$ & $*$ & $*$ \\
\hline & \multirow{2}{*}{ 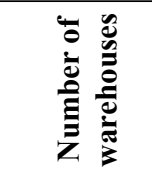 } & Two & & & & & & & & & & & \\
\hline & & One & $*$ & $*$ & $*$ & $*$ & $*$ & $*$ & $*$ & $*$ & $*$ & $*$ & $*$ \\
\hline & \multirow{2}{*}{ कू } & Lost sales & & & & & & & & & & & \\
\hline & & Backlog & & $*$ & & & & & & & & & $*$ \\
\hline & \multirow{2}{*}{ 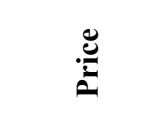 } & Discount & & & $*$ & & & & & & & & \\
\hline & & Price increase & & & & & & & & & $*$ & & \\
\hline & \multirow{2}{*}{ 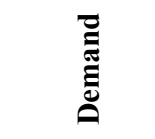 } & Certain & $*$ & $*$ & $*$ & $*$ & & $*$ & & & & & \\
\hline & & Uncertain & & & & & & & $*$ & $*$ & $*$ & $*$ & $*$ \\
\hline & \multirow{2}{*}{ 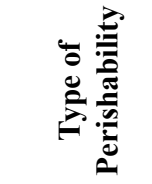 } & Obsolescence & $*$ & $*$ & $*$ & $*$ & & $*$ & $*$ & & & & \\
\hline & & Deterioration & & & & & & & & $*$ & & $*$ & $*$ \\
\hline & \multicolumn{2}{|l|}{ Article } & 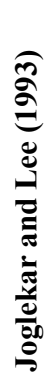 & 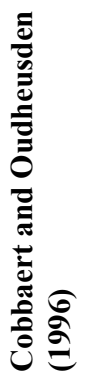 & 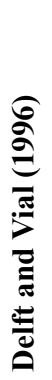 & 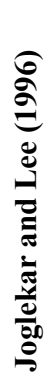 & 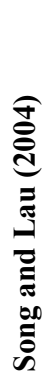 & 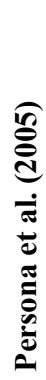 & 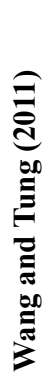 & 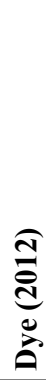 & 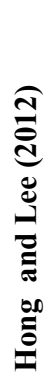 & 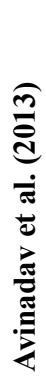 & 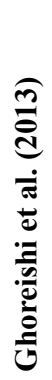 \\
\hline
\end{tabular}




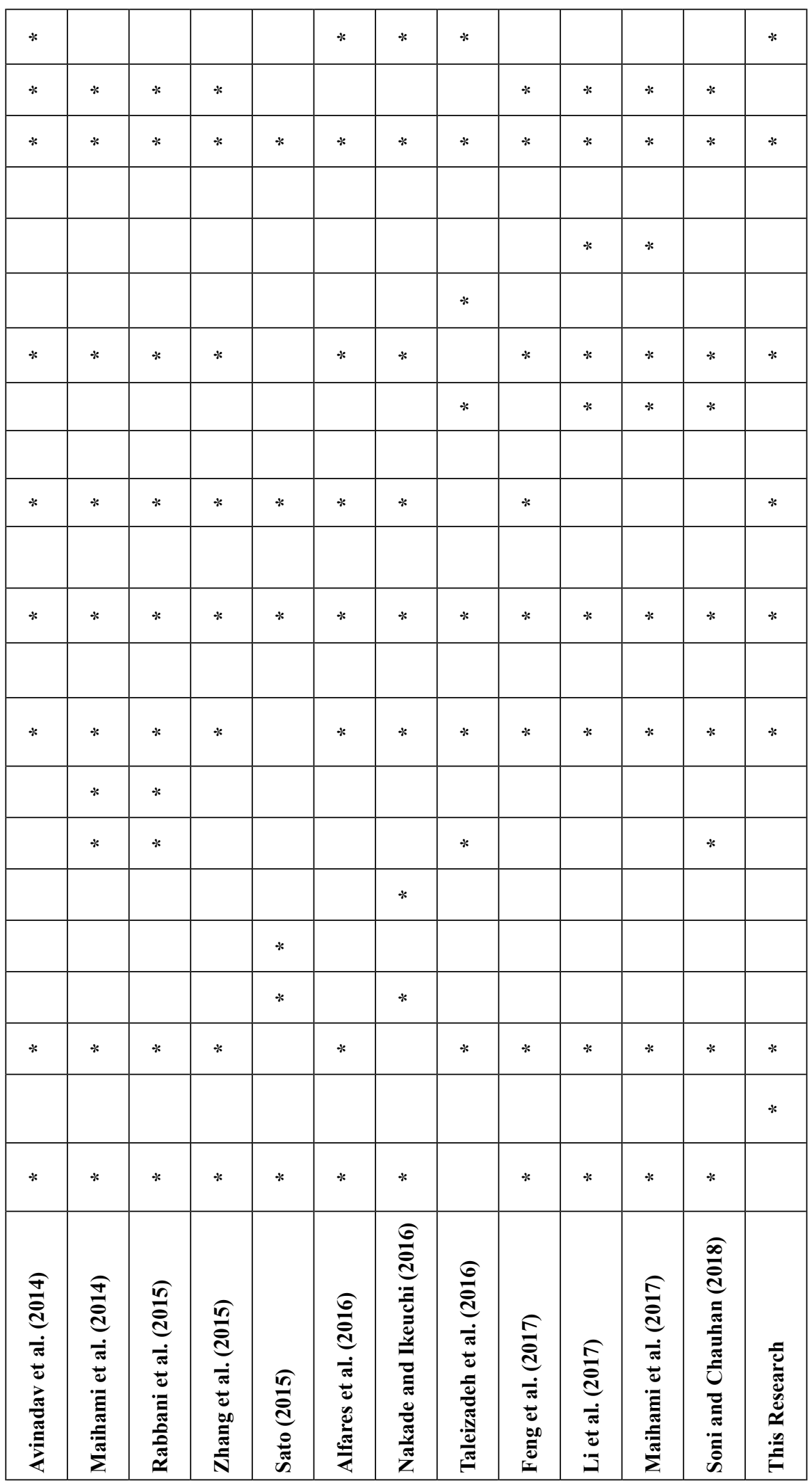


As observed in Table 1, unlike researches on inventory deteriorating items, there are not many researches on using pricing in inventory model of obsolescence items. This research tries to answer the question, in conditions with the presence of occurring obsolescence for inventory items, how many items should be ordered and at what price should the items be sold.

\section{ASSUMPTIONS AND NOTATIONS}

Considering an inventory control system with obsolete products and price-dependent demand, the introduced model was developed based on the following assumptions.

- $\quad$ Shortage is not allowed

- $\quad$ Obsoleted products are sold at a price less than the purchasing costs.

- The annual demand rate is constant.

- A single product is considered.

- $\quad$ Lead-time is zero, and the replenishment rate is infinite.

- Obsolescence happens suddenly.

- The obsolescence product lifetime is exponential.

- The planning horizon is infinite.

Meanwhile, the following notations are being used for developing the mathematical model.

\section{PARAMETERS:}

t: The time that product becomes obsolete (Year)

L: Expected product lifetime (years)

$\mathrm{R}$ : Demand function, which is defined as: $\mathrm{R}=\mathrm{R}_{0} \mathrm{~b} \mathrm{e}^{-\mathrm{a} * \mathrm{p}}$

$\mathrm{R}_{0}$ : Fixed parameter of demand function,

$\mathrm{a}, \mathrm{b}$ : Elastic parameters of demand function $(\mathrm{a}<1)$

A: The ordering cost $(\$)$

$\mathrm{h}$ : The holding cost per unit of inventory held (\$/year)

C: The purchasing cost per unit (\$)

$\varphi$ : Selling price of obsoleted products per unit (\$/year)

$\delta$ : The probability that an obsolescence does not occurred during the order cycle.

$\pi_{\mathrm{c}}$ : Total retailer's profit per cycle

$\pi_{\mathrm{L}}$ : Total retailer's profit in planning horizon.

\section{DECISION VARIABLES}

Q: Order quantity per cycle

p: The selling price per unit (\$). 


\section{MATHEMATICAL MODEL}

The proposed model consists of the proceeds from the sale of products, holding cost, ordering cost, purchasing cost, and salvage values of obsolete products per cycle to maximize the profit of the retailer, as discussed below.

Since the proposed objective function is nonlinear and bivariate, a mathematical powerful software is needed to solve the model. Among the available mathematical software, MATLAB, Maple, and Mathematica were evaluated. Mathematica has a better display power and performance, because it is technically simpler and has the capability of drawing 3D graphs as well as the exact solution of linear and nonlinear problems. Therefore, in this research, this software has been used to solve the numerical examples.

1. Sales revenue (denoted by Vs):

Sales revenue can be calculated based on obsolescence occurring time as follows:

Case 1: during cycle time $[0<\mathrm{t}<\mathrm{T}]$

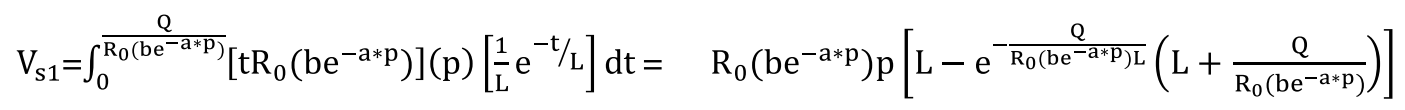

Case 2: after cycle time $[\mathrm{t}>\mathrm{T}]$ :

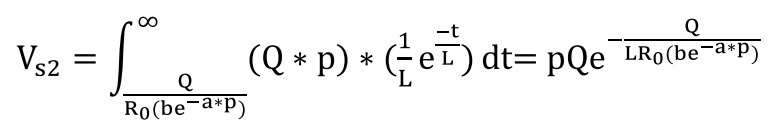

2. Salvage values of obsoleted products (denoted by $V_{\varphi}$ )

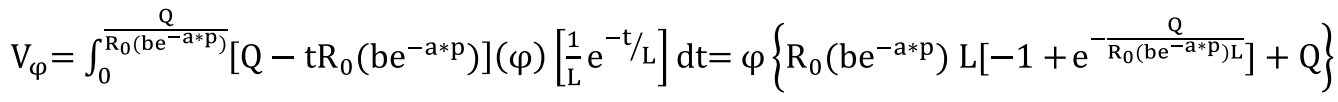

3. Cost of purchasing (denoted by $\mathrm{CP})$ :

$$
C P=c^{*} Q
$$

4. Cost of placing orders (denoted by OC):

$\mathrm{OC}=\mathrm{A}$

5. Holding cost (denoted by $\mathrm{CH}$ ), which is similarly calculated based on obsolescence occurring time as follows:

Case 1: obsolescence during cycle time $[0<\mathrm{t}<\mathrm{T}]$ :

$$
\begin{aligned}
& \mathrm{CH} 1=\int_{0}^{\frac{\mathrm{Q}}{\left.\mathrm{R}_{0}\left(\mathrm{be}^{-\mathrm{a} * \mathrm{p}}\right)\right)}}\left[\mathrm{Qh}-\frac{\mathrm{tR}_{0}\left(\mathrm{be}^{-\mathrm{a} * \mathrm{p}}\right)}{2}\right](\mathrm{ht})\left[\frac{1}{\mathrm{~L}} \mathrm{e}^{-\mathrm{t} / \mathrm{L}}\right] \mathrm{dt}=\frac{\mathrm{h}}{2}\left\{2 \mathrm { L } \left[-\mathrm{LR}_{0}\left(\mathrm{be}^{-\mathrm{a} * \mathrm{p}}\right)+\right.\right. \\
& \left.\mathrm{Q}]+\frac{\mathrm{e}^{-\frac{\mathrm{Q}}{\mathrm{R}_{0}(\mathrm{be}-\mathrm{a} * \mathrm{p}) \mathrm{L}}}\left[2\left(\mathrm{R}_{0}\left(\mathrm{be}^{-\mathrm{a} * \mathrm{p}}\right)^{2} \mathrm{~L}^{2}-\mathrm{Q}^{2}\right]\right.}{\mathrm{R}_{0}\left(\mathrm{be}^{-\mathrm{a} * \mathrm{p}}\right)}\right\}
\end{aligned}
$$

Case 2: obsolescence after cycle time $[\mathrm{t}>\mathrm{T}]$ : 


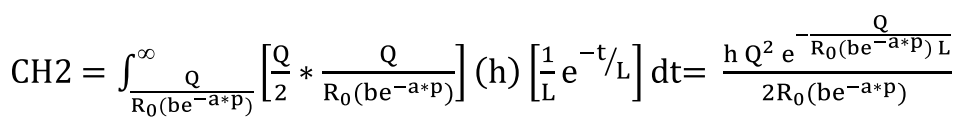

At result, the total retailer's profit per cycle can be obtained as follows:

$$
\begin{aligned}
& \pi_{c}(\mathrm{Q}, \mathrm{p})=\mathrm{R}_{0}\left(\mathrm{be} \mathrm{e}^{-\mathrm{a} * \mathrm{p}}\right) \mathrm{pL}\left(1-\mathrm{e}^{-\frac{\mathrm{Q}}{\mathrm{R}_{0}\left(\mathrm{be}^{-\mathrm{a} * \mathrm{p}}\right) \mathrm{L}}}\right)-\{\mathrm{A}+\mathrm{c} * \mathrm{Q}+(\mathrm{h} * \mathrm{~L}-\varphi) * \\
& \left.\left(\mathrm{Q}-\mathrm{R}_{0}\left(\mathrm{be}^{-\mathrm{a} * \mathrm{p}}\right) * \mathrm{~L} *\left(1-\mathrm{e}^{-\frac{\mathrm{Q}}{\mathrm{R}_{0}\left(\mathrm{be}^{-\mathrm{a} * \mathrm{p}}\right) \mathrm{L}}}\right)\right)\right\}
\end{aligned}
$$

Meanwhile, considering exponentially definition of product lifetime function and its memoryless property, the retailer's profit at the beginning of each cycle in the absence of obsolescence would be equal to the retailer's profit of the previous cycle. Therefore,

$$
\pi_{\mathrm{L}}(\mathrm{Q}, \mathrm{p})=\pi_{\mathrm{c}}(\mathrm{Q}, \mathrm{p})+\pi_{\mathrm{c}}(\mathrm{Q}, \mathrm{p}) \delta+\pi_{\mathrm{c}}(\mathrm{Q}, \mathrm{p})(\delta)^{2}+\ldots \Rightarrow \pi_{\mathrm{L}}=\frac{\pi_{\mathrm{c}}(\mathrm{Q}, \mathrm{p})}{(1-\delta)}
$$

where

$$
\delta=\int_{\frac{\mathrm{Q}}{\mathrm{R}_{0}\left(\mathrm{be}^{-\mathrm{a} * \mathrm{p}}\right)}}^{\infty}\left[\frac{1}{\mathrm{~L}} \mathrm{e}^{-\frac{\mathrm{t}}{\mathrm{L}}}\right] \mathrm{dt}=\mathrm{e}^{-\frac{\mathrm{Q}}{\mathrm{R}_{0}\left(\mathrm{be}^{-\mathrm{a} * \mathrm{p}) \mathrm{L}}\right.}}
$$

and hence the total retailer's profit at the infinite horizon time would be

$$
\pi_{L}(\mathrm{Q}, \mathrm{p})=\frac{\pi_{\mathrm{c}}(\mathrm{Q}, \mathrm{p})}{1-\mathrm{e}^{-\frac{\mathrm{Q}}{\mathrm{R}_{0}\left(\mathrm{be}^{-\mathrm{a} * \mathrm{p}}\right) \mathrm{L}}}}=\mathrm{R}_{0}\left(\mathrm{be}^{-\mathrm{a} * \mathrm{p}}\right) \mathrm{L}(\mathrm{h} * \mathrm{~L}-\varphi+\mathrm{p})-\frac{\mathrm{A}+(\mathrm{h} * \mathrm{~L}-\varphi+\mathrm{c}) \mathrm{Q}}{\left(1-\mathrm{e}^{-\frac{\mathrm{Q}}{\mathrm{R}_{0}\left(\mathrm{be}^{-\mathrm{a} * \mathrm{p}}\right) \mathrm{L}}}\right)}
$$

\section{SOLUTION METHOD}

Since the objective function of the model is complex and it is very difficult to provide a complete solution and prove the concavity for Eq. 11, to obtain the positive roots and prove the concavity of the objective function, the Taylor series approximation is used as follows:

Considering the Taylor series approximation $\mathrm{e}^{-\frac{\mathrm{Q}}{\mathrm{RL}}} \approx 1-\frac{\mathrm{Q}}{\mathrm{RL}}+\frac{1}{2}\left(\frac{\mathrm{Q}}{\mathrm{RL}}\right)^{2}$, the objective function can be simplified as follows:

$$
\pi_{L}(Q, p)=R_{0}\left(b e^{-a * p}\right) L(\vartheta-c+p)-\frac{2 R_{0}^{2}\left(b e^{-2 a * p}\right) L^{2}(A+\vartheta Q)}{\left(2 R_{0}\left(b e^{-a * p}\right) L Q-Q^{2}\right)}
$$

Then, the optimal w value of Q is simply obtained as follows:

$$
\begin{aligned}
& \frac{\partial \pi_{\mathrm{L}}}{\partial \mathrm{Q}}=-\left(\frac{2 \mathrm{R}_{0}(\mathrm{be}-\mathrm{a} * \mathrm{p}) \mathrm{L}}{2 \mathrm{R}_{0}\left(\mathrm{be}^{-\mathrm{a} * \mathrm{p}}\right) \mathrm{LQ}-\mathrm{Q}^{2}}\right)^{2}\left(\frac{1}{2} \vartheta \mathrm{Q}^{2}+\mathrm{AQ}-\mathrm{AR}_{0}\left(\mathrm{be}^{-\mathrm{a} * \mathrm{p}}\right) \mathrm{L}\right)=0 \Rightarrow \mathrm{Q}^{*}= \\
& \frac{-\mathrm{A}+\sqrt{\mathrm{A}^{2}+2 \mathrm{AR}_{0}\left(\mathrm{be}^{-\mathbf{a} * \mathrm{p}}\right) \mathrm{L} \vartheta}}{\vartheta}
\end{aligned}
$$


where $\vartheta=\mathrm{hL}+\mathrm{c}-\varphi$.

The second-order derivative on Q can be also obtained as follows:

$\left.\frac{\partial^{2} \pi_{\mathrm{L}}}{\partial \mathrm{Q}^{2}}\right|_{\left(\mathrm{Q}^{*}\right)}=-\left(2 \mathrm{R}_{0}\left(\mathrm{be}^{-\mathrm{a} * \mathrm{p}}\right) \mathrm{L}\right)^{2} \frac{\mathrm{Q}^{* 3} \vartheta+\mathrm{A}\left(2 \mathrm{R}_{0}\left(\mathrm{be}^{-\mathrm{a} * \mathrm{p}}\right) \mathrm{L}-2 \mathrm{Q}^{*}\right)^{2}+\mathrm{A}\left(2 \mathrm{R}_{0}\left(\mathrm{be}^{-\mathrm{a} * \mathrm{p}}\right) \mathrm{LQ}^{*}-\mathrm{Q}^{* 2}\right)}{\left(2 \mathrm{R}_{0}\left(\mathrm{be}^{-\mathrm{a} * \mathrm{p}}\right) \mathrm{LQ} \mathrm{Q}^{*}-\mathrm{Q}^{* 2}\right)^{3}}$

$\pi_{\mathrm{L}}$ is concave in $\mathrm{Q}$ only if $\frac{\partial^{2} \pi_{\mathrm{L}}}{\partial \mathrm{Q}^{2}} \leq 0$ for all $\mathrm{Q}$.

Given that the amount of demand is always higher than the order quantity and $\mathrm{L}>1, \mathrm{R}_{0}\left(\mathrm{be}^{-\mathrm{a} * \mathrm{p}}\right) \mathrm{L}>\mathrm{Q}$ and then $2 \mathrm{R}_{0}$ (be $\left.\mathrm{b}^{-\mathrm{a} * \mathrm{p}}\right) \mathrm{LQ}>\mathrm{Q}^{2}$. Hence, Eq. (14) is negative in $\mathrm{Q}^{*}$ and then it is concluded that $\mathrm{Q}^{*}$ is a global solution for optimization model.

\section{Theorem:}

For any given $\mathrm{Q}^{*}$ :

(a) The objective function has a unique solution on $\mathrm{p}$.

(b) The solution in (a) satisfies the local optimal conditions.

\section{Proof:}

Based on Mahami (2014), Dye (2007), Chang et al. (2006), and Yang et al. (2009), due to high complexity of the taken derivatives, instead of straight forward proof, the theorem was pursued on the objective function by substituting the optimal Q in (12) and, consequently, obtaining an objective function response with only selling price (p). For any $Q^{*}$ the first-order necessary condition for $\pi_{L}\left(Q^{*}, p\right)$ to be maximized is $\frac{\partial \pi_{L}}{\partial p}=0$, that is,

$$
\frac{\partial \pi_{\mathrm{L}}\left(\mathrm{Q}^{*}, \mathrm{p}\right)}{\partial \mathrm{p}}=\mathrm{LR}_{0}\left(\mathrm{be}^{-\mathrm{a} * \mathrm{p}}\right)-\mathrm{aLR}_{0}\left(\mathrm{be}^{-\mathrm{a} * \mathrm{p}}\right)(\mathrm{hL}+\mathrm{p}-\varphi)-\frac{4 \mathrm{aL}^{2} \mathrm{R}_{0}{ }^{2}\left(\mathrm{be}^{-2 \mathrm{a} * \mathrm{p}}\right)\left(\mathrm{A}+\mathrm{Q}^{*} \vartheta\right)\left(\mathrm{Q}^{* 2}-\mathrm{LQ}^{*} \mathrm{R}_{0}\left(\mathrm{be}^{-\mathrm{a} * \mathrm{p}}\right)\right.}{\left(-\mathrm{Q}^{* 2}+2 \mathrm{LQ}^{*} \mathrm{R}_{0}\left(\mathrm{be}^{-\mathrm{a} * \mathrm{p}}\right)\right)^{2}}
$$

In addition, the second-order derivative on $\mathrm{p}$ can be obtained as follows:

$$
\begin{aligned}
& \frac{\partial^{2} \pi_{\mathrm{L}}\left(\mathrm{Q}^{*}, \mathrm{p}\right)}{\partial \mathrm{p}^{2}}=-\mathrm{aR}_{0}\left(\mathrm{be} \mathrm{e}^{-\mathrm{a} * \mathrm{p}}\right) \mathrm{L}(2-\mathrm{a}(\mathrm{hL}+\mathrm{p}-\varphi))- \\
& \frac{4 \mathrm{a}^{2} \mathrm{R}_{0}{ }^{2}\left(\mathrm{be}^{-2 \mathrm{a} * \mathrm{p}}\right) \mathrm{L}^{2} \mathrm{Q}^{*}\left(\mathrm{~A}+\mathrm{Q}^{*} \vartheta\right)}{\left(-\mathrm{Q}^{* 2}+2 \mathrm{R}_{0}\left(\mathrm{be}^{-\mathrm{a} * \mathrm{p}}\right) \mathrm{LQ}^{*}\right)^{3}}\left[2 \mathrm{Q}^{* 3}+\mathrm{R}_{0}\left(\mathrm{be}^{-\mathrm{a} * \mathrm{p}}\right) \mathrm{LQ}^{*}\left(-3 \mathrm{Q}^{*}+2 \mathrm{R}_{0}\left(\mathrm{be}^{-\mathrm{a} * \mathrm{p}}\right) \mathrm{L}\right)\right]
\end{aligned}
$$

In this equation, given that, in real condition of an inventory problem, generally more than one order is placed, we can consider $\mathrm{R}_{0}\left(\mathrm{be}^{-\mathrm{a} * \mathrm{p}}\right) \mathrm{L}=\mathrm{kQ} \mathrm{Q}^{*}$ where $\mathrm{k}>1$ and hence $2 \mathrm{R}_{0}\left(\mathrm{be}^{-\mathrm{a} * \mathrm{p}}\right) \mathrm{L}-3 \mathrm{Q}^{*}>0$.

On the other hand, it is evident that the selling price per unit (p) and selling price of obsoleted products per unit $(\varphi)$ are more than the holding cost per unit in the expected product lifetime $(\mathrm{hL})$ and so $\mathrm{hL}-\varphi<\mathrm{p}$ or in other words, $\mathrm{a}(\mathrm{hL}-\varphi)<\mathrm{ap}<1$ and hence $2-\mathrm{a}(\mathrm{hL}+\mathrm{p}-\varphi)>0$.

Considering the two above inequalities, $\frac{\partial^{2} \pi_{\mathrm{L}}}{\partial \mathrm{p}^{2}}<0$

Consequently, $\pi_{L}\left(Q^{*}, p\right)$ is concave on $p$ for any given $Q^{*}$, and hence the optimal $p$ obtained from (15) would be unique. As result, there is a unique value of $\pi_{\mathrm{L}}\left(\mathrm{p}^{*}\right)$, which maximizes $\pi_{\mathrm{L}}\left(\mathrm{Q}^{*}, \mathrm{p}\right)$ and the theorem is proved. 


\section{NUMERICAL EXAMPLE}

Now, after introducing the mathematical model, to illustrate the solution procedure and the results, the following numerical examples are solved with one of the mathematical software programs. For this reason, Mathematica software was used to solve the numerical examples, since this software is particularly useful for solving complex nonlinear problems, by simply obtaining the first and second time derivatives. In addition, the software is capable of drawing $3 \mathrm{D}$ graphs of the results, which is useful for this study in showing the optimal results.

The results are obtained by "FindMaximum" in Mathematica 6.0, and the illustration is plotted using "Plot3D" in Mathematica 6.0.

Example 1: This example is based on the following parameters:

$$
A=250, b=1, a=0.005, R_{0}=1000, h=6, L=4, c=50, \varphi=15
$$

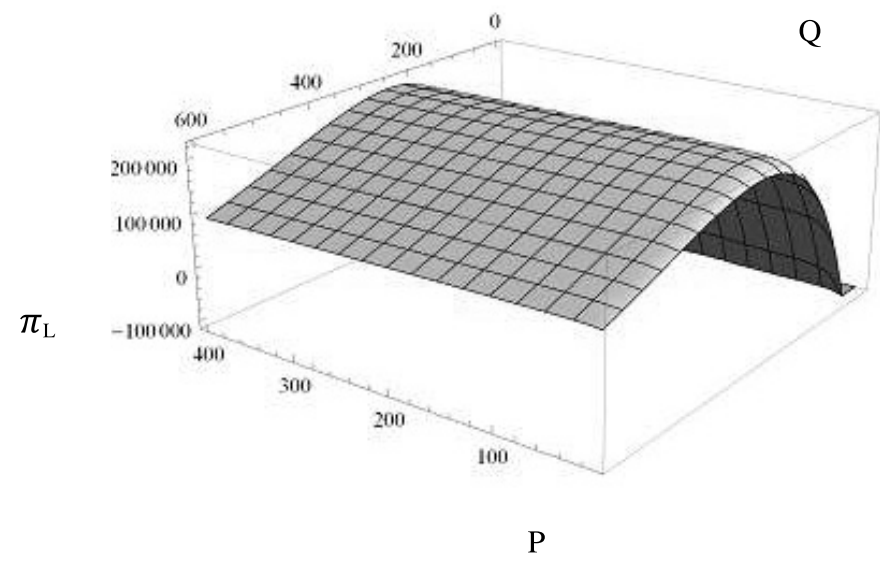

Figure 1. Changes in the retailer's total profit compared to the selling price and order quantity.

As shown in Fig. 1, the objective function is concave for the given parameters at the optimal price with $\mathrm{Q}=96.67$. The optimum value is 253.349 . Of course, the curve for much more intervals is depicted in all three dimensions, but there was no change in concavity of the graph.

As shown in Fig. 1, the objective function is concave for the given parameters at the optimal price with $\mathrm{Q}=96.67$. The optimum value is 253.349 . Of course, the curve for much more intervals is depicted in all three dimensions, but there was no change in the concavity of the graph.

Example 2: This example is based on the following parameters:

$$
A=200, b=1, a=0.005, R_{0}=1000, A=250, h=6, L=4, c=200, \varphi=150, Q^{*}=150
$$

In this example, it is attempted to show the optimal P for optimal Q. The numerical results are shown in Fig. 2, which indicates the concavity of $\pi_{\mathrm{L}}\left(\mathrm{p} \mid \mathrm{Q}^{*}\right)$. As a result, it is ensured that the local maximum obtained here is indeed the global maximum solution. 


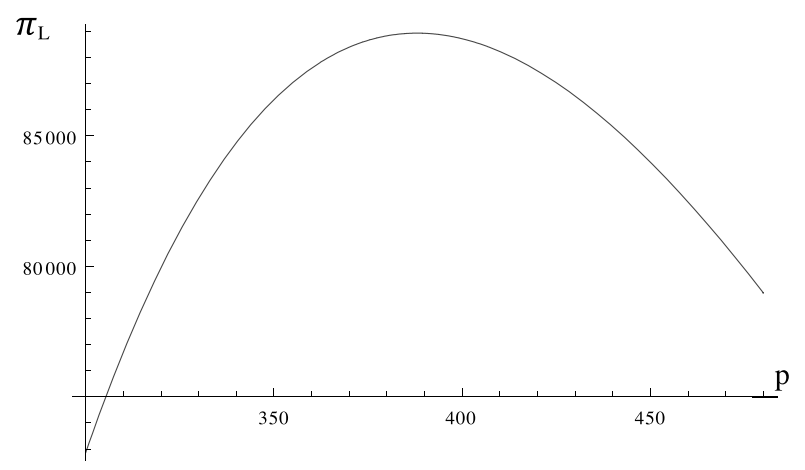

Figure 2. Graphical representation of $\pi_{\mathrm{L}}\left(\mathrm{p} \mid \mathrm{Q}^{*}\right)$.

\section{SENSITIVITY ANALYSIS}

To perform sensitivity analysis, the cost parameters and lifetime have been changed, and their effects on order quantity, selling price, and total profit are examined as shown in the following examples:

Example 1: now the effects of changes in the system parameters on the $\mathrm{p}^{*}, \mathrm{Q}^{*}$, and $\pi_{L}$ by changing in $\varphi, \mathrm{h}, \mathrm{L}$, and $\mathrm{C}$ are addressed. The computational results are shown in Table 2.

Table 2. Sensitivity analysis by changing h, $\varphi, \mathrm{L}, \mathrm{C}$.

\begin{tabular}{ccccc}
\hline Parameter & value & $\pi_{\mathrm{L}}$ & $\mathrm{p}$ & $\mathrm{Q}$ \\
\hline \multirow{4}{*}{$\mathrm{h}$} & 10 & 135971 & 350.995 & 40.7202 \\
& 15 & 135529 & 351.348 & 38.4428 \\
& 20 & 135109 & 351.687 & 36.5052 \\
& 25 & 134707 & 352.012 & 34.8304 \\
& 30 & 134321 & 352.326 & 33.3638 \\
& 35 & 133949 & 352.631 & 32.0654 \\
& & & & \\
& 120 & 138717 & 348.856 & 64.8555 \\
$\varphi$ & 100 & 138060 & 349.359 & 56.7517 \\
& 80 & 137473 & 349.813 & 51.0719 \\
& 60 & 136936 & 350.232 & 46.8061 \\
& 40 & 136438 & 350.625 & 43.4501 \\
& 20 & 135971 & 350.995 & 40.7202 \\
& & & & \\
& 20 & 181958 & 294.215 & 60.1903 \\
$\mathrm{C}$ & 30 & 181633 & 294.408 & 57.3903 \\
& 40 & 181321 & 294.594 & 54.9454 \\
& 50 & 181021 & 294.774 & 52.7865 \\
& 60 & 180731 & 294.948 & 50.8617 \\
& 70 & 180451 & 295.118 & 49.1314 \\
& & & & \\
& 7 & 317981 & 294.509 & 59.5866 \\
& 6 & 272451 & 294.509 & 58.4606 \\
& 5 & 226896 & 294.532 & 56.9799 \\
& 4 & 181321 & 294.594 & 54.9454 \\
& 3 & 135729 & 294.729 & 51.9716 \\
& 2 & 90134.4 & 295.035 & 47.1887 \\
\hline \multirow{4}{*}{ L } & & & & \\
& & & &
\end{tabular}


Example 2: This time, the effects of changes in the system parameters on the $\mathrm{p}^{*}, \mathrm{Q}^{*}$, and $\pi \mathrm{L}$ are investigated by taking into account the interactions of the parameters in $\varphi, \mathrm{h}, \mathrm{L}$, and $\mathrm{C}$. The computational results for $\mathrm{C}=50 \$$ and $\mathrm{C}=200 \$$ are shown in Table 3 and Table 4, respectively.

Table 3. Sensitivity analysis by changing $\mathrm{L}, \mathrm{h}, \varphi$ in $\mathrm{C}=50 \$$.

\begin{tabular}{|c|c|c|c|c|c|c|c|}
\hline \multicolumn{2}{|c|}{ Parameter } & \multicolumn{2}{|c|}{$\varphi=20$} & \multirow[b]{2}{*}{$\pi_{\mathrm{L}}$} & \multicolumn{3}{|c|}{$\varphi=30$} \\
\hline$h$ & $\mathrm{~L}$ & $\mathrm{Q}$ & $\mathrm{p}$ & & $\mathrm{Q}$ & $\mathrm{p}$ & $\pi_{\mathrm{L}}$ \\
\hline \multirow{2}{*}{2.5} & 2 & 127.606 & 251.711 & 452529 & 141.009 & 251.47 & 453276 \\
\hline & 4 & 150.297 & 251.399 & 906928 & 160.676 & 251.237 & 907848 \\
\hline \multirow{2}{*}{6} & 2 & 99.8994 & 251.673 & 450293 & 105.972 & 251.464 & 450881 \\
\hline & 4 & 109.854 & 251.435 & 901455 & 113.739 & 251.302 & 902156 \\
\hline \multirow{2}{*}{10} & 2 & 83.1886 & 251.69 & 448172 & 86.6123 & 251.506 & 448668 \\
\hline & 4 & 88.7346 & 251.518 & 896365 & 90.7568 & 251.402 & 896955 \\
\hline
\end{tabular}

Table 4. Sensitivity analysis by changing $L, h, \varphi$ in $C=200 \$$.

\begin{tabular}{cccccccc}
\hline \multicolumn{2}{c}{ Parameter } & \multicolumn{3}{c}{$\varphi=100$} & \multicolumn{3}{c}{$\varphi=150$} \\
\hline$h$ & $\mathrm{~L}$ & $\mathrm{Q}$ & $\mathrm{p}$ & $\pi_{\mathrm{L}}$ & $\mathrm{Q}$ & $\mathrm{p}$ & $\pi_{\mathrm{L}}$ \\
\hline \multirow{2}{*}{10} & 2 & 54.7548 & 404.094 & 209484 & 68.3036 & 403.087 & 211182 \\
& 4 & 68.6213 & 403.304 & 421905 & 80.800 & 402.598 & 424100 \\
& & & & & & & \\
\multirow{2}{*}{24} & 2 & 46.2568 & 404.321 & 207869 & 53.6492 & 403.406 & 209284 \\
& 4 & 53.8189 & 403.712 & 417740 & 59.1822 & 403.102 & 419484 \\
& & & & & & & \\
\multirow{2}{*}{40} & 2 & 40.1352 & 404.613 & 206258 & 44.7181 & 403.779 & 403.644 \\
& 4 & 44.811 & 404.187 & 413722 & 47.799 & 207486 & 415210 \\
\hline
\end{tabular}

The results show that the retailer's total profit is decreased by reducing the lifetime of the product (L), which is natural because the retailer is forced to keep more products in less time, resulting in lower profit. However, the optimal price does not change much, since changing $L$ does not affect demand changes, whereas the optimal order quantity is decreased since the product is obsolete more quickly by reducing L; therefore, the retailer orders fewer products to deal with the risk of obsolescence.

Besides, the retailer's total profit is reduced by increasing $\mathrm{C}$, because with the increase in $\mathrm{C}$, even though the value of $\mathrm{p}$ is increased, the effect on demand reduction is much higher, and so the total profit is reduced.

Increasing $\mathrm{C}$ decreases the amount of ordering, because as the item purchasing cost increases, the retailer must sell the product at a higher price. Increasing the sales price reduces demand, and decreasing demand reduces the order quantity.

Meanwhile, increasing $\varphi$ will naturally cause an increase in retailer revenues and a relative increase in an optimal order quantity, but it does not affect the selling price.

Finally, increasing h, due to the direct impact on increasing holding cost, reduces optimal order quantity and consequently reduces the total profit of retailers. However, since it does not affect the amount of customer demand, it does not change the selling price so much. 
In this section, several numerical experiments were performed to analyze the decision variables including the price and order quantity and obtain the optimal value of objective function, based on the changes in the values of some critical parameters of the model. The results are presented in detail in Tables 2, 3, and 4. Specifically, in this section, sensitivity analysis is performed on $\mathrm{L}, \mathrm{h}, \mathrm{C}$, and $\varphi$ parameters. Given that these parameters have an important and decisive influence on the behavior of objective function, decision making, and management solutions, they are selected for sensitivity analysis. According to Table 2, the increased risk of obsolescence (i.e., L reduction) reduces the order quantity. Therefore, at a time when the risk of obsolescence is high, it is better to purchase less items from the beginning and store them in the stock. Besides, if the holding cost per unit of an item is high, fewer items are kept in the stock and consequently, the order quantity decreases. Also, if the sale price of the obsolete items is higher, it is better to order more from the beginning of the period.

\section{CONCLUSION}

In recent years, the technological development, strong market competition, and acceleration of innovation have greatly reduced the product lifetime, and hence the products (especially hi-tech products such as electronic devices, cell phones, personal computers, and information systems) are obsolete faster.

On the other hand, studies show that inventory control policies, without considering the selling price as decision variables, are not able to optimize the profit correctly. Therefore, concurrent attention to price and inventories is not only useful but also essential, since simultaneous decision with these two factors helps optimize the system and increase the profit.

Accordingly, in this study, a combination of pricing and inventory control for the products exposed to obsolescence was introduced considering price-dependent demand.

The problem of pricing the obsolete items is of particular importance due to the sudden drop in their demand. But the objective function of inventory control problems with obsolete items is of considerable complexity. This complexity is due to the possible nature of the obsolescence process. The probable period of obsolescence for an item is usually considered in the form of an exponential distribution function. Therefore, the objective function in these types of problems is usually a complex nonlinear model. For this reason, the pricing of obsolete items has not been seriously investigated so far.

In modeling, after determining the terms of inventory control costs and the revenue proceeds from sold products, the retailer's total profit was developed, and then the model was solved using the mathematical methods. Meanwhile, numerical examples were introduced to analyze the results, and sensitivity analyses were performed on the optimal order quantity and selling price.

There are some limitations is this study. We had to use some simplifications in the model by using Taylor series approximation. Meanwhile, in proving the concavity, we could not use Hessian matrix directly and instead, a replacement approach was used to solve the problem. After all, there are many specifications and conditions in the real world that have not been addressed in this research. For example, the demand rate can be defined in both time and price-dependent modes considering the effects of product lifetime on the demand. Obsolescence can be assumed gradually (instead of suddenly) as a function of time. Moreover, the model can be more extended into real-world conditions by considering concepts such as the time value of money and delay in payments. Finally, the various types of shortages can be added to the model, and the model can be developed based on these new restrictions.

\section{REFERENCES}

Abad, P.L. 2003. Optimal pricing and lot-sizing under conditions of perishability, finite production and partial backordering and lost sale. European Journal of Operational Research, 144(3): 677-685.

Alfares, H.K. \& Ghaithan, A.M. 2016. Inventory and pricing model with price-dependent demand, time-varying holding cost, and quantity discounts. Computers \& Industrial Engineering, 94: 170-177. 
Avinadav, T., Herbon, A. \& Spiegel, P. 2013. Optimal ordering and pricing policy for demand functions that are separable into price and inventory age. International Journal of Production Economics, 155: 406-417.

Avinadav, T., Herbon, A. \& Spiegel, P. 2014. Optimal inventory policy for a perishable item with demand function sensitive to price and time. International Journal of Production Economics, 144: 497-506.

Azadi, Z., Eksioglu, S.D., Eksioglu, B. \& Palak, G. 2019. Stochastic optimization models for joint pricing and inventory replenishment of perishable products. Computers \& Industrial Engineering, 127: 625-642.

Chen, Zh. 2019. Reprint of "Optimization of production inventory with pricing and promotion effort for a single-vendor multibuyer system of perishable products”. International Journal of Production Economics, 209 (2019): 285-301.

Cobbaert, K. \& Oudheusden, D.V. 1996. Inventory models for fast moving spare parts subject to "sudden death" obsolescence. International Journal of Production Economics, 44: 239-248.

Delft, C.V. \& Vial, J.P. 1996. Discounted costs, obsolescence and planned stock outs with the EOQ formula. International Journal of Production Economics, 44: 255-265.

Dye, C.Y. 2012. A finite horizon deteriorating inventory model with two-phase pricing and time-varying demand and cost under trade credit financing using particle swarm optimization. Swarm and Evolutionary Computation, 5: 37-53.

Feng, L., Li. R., Chan, Y.L., Chang, C.T. \& Cárdenas-Barrón, L.E. 2017. Pricing and lot-sizing polices for perishable goods when the demand depends on selling price, displayed stocks, and expiration date. International Journal of Production Economics 185:11-20.

Ghoreishi, M., Arshsadi khamseh, A. \& Mirzazadeh, A. 2013. Joint optimal pricing and inventory control for deteriorating items under inflation and customer returns. Journal of Industrial Engineering, 2013: 1-7.

Goyal, S.K. \& Giri, B.C., 2001. Recent trends in modeling of deteriorating inventory. European Journal of Operational Research, 134: 1-16.

Hong, K.S. \& Lee, C. 2013. Optimal pricing and guaranteed lead time with lateness penalties. International Journal of Industrial Engineering, 20(1-2): 153-162.

Joglekar, P. \& Lee, P. 1996. A profit-maximization model for a retailer's stocking decision on products subject to sudden obsolescence. Production and Operations Management, 5(3): 288-294.

Joglekar, P. \& Lee, P. 1993. An exact formulation of inventory costs and optimal lot size in face of sudden obsolescence. Operations Research Letters, 14: 283-290.

Li, R., Chan, Y-L., Chang, C-T. \& Cárdenas-Barrón, L.E. 2017. Pricing and lot-sizing policies for perishable products with advance-cash-credit payments by a discounted cash-flow analysis. International Journal of Production Economics, 193: 578589.

Mahmoodi, A. 2019. Joint pricing and inventory control of duopoly retailers with deteriorating items and linear demand. Computers \& Industrial Engineering, 132: 36-46.

Maihami, R., Karimi, B. \& Fatemi Ghomi, S.M.T. 2017. Effect of two-echelon trade credit on pricing-inventory policy of noninstantaneous deteriorating products with probabilistic demand and deterioration functions. Annals of Operations Research, 257: $237-273$.

Maihami, R. \& Karimi, B. 2014. Optimizing the pricing and replenishment policy for non-instantaneous deteriorating items with stochastic demand and promotional efforts. Computers \& Operations Research, 51: 302-312.

Nakade, N. \& Ikeuchi, K. 2016. Optimal ordering and pricing on clearance goods. International Journal of Industrial Engineering, 23(3): 155-165.

Persona, A., Grassi, A. \& Catena, M. 2005. Consignment stock of inventories in the presence of obsolescence. International Journal of Production Research, 43: 4969-4988.

Raafat, F., 1991. Survey of literature on continuously deteriorating inventory models. Journal of Operational Research Society, 42(1): 27-37.

Rabbani, M., Pourmohammad Zia, N. \& Rafiei, H. 2015. Coordinated replenishment and marketing policies for non-instantaneous stock deterioration problem. Computers \& Industrial Engineering, 88: 49-62. 
Sato, K. 2015. Dynamic pricing with customer purchase postponement. International Journal of Industrial Engineering, 22(1): 159-170.

Song, Y. \& Lau, H.C. 2004. A periodic-review inventory model with application to the continuous-review obsolescence problem. European Journal of Operational Research, 159:110-120.

Soni, H.N. \& Chauhan, A.D. 2018. Joint pricing, inventory, and preservation decisions for deteriorating items with stochastic demand and promotional efforts. Journal of Industrial Engineering International Online, 1-13.

Taleizadeh, A.A., Sadat Kalantari, S. \& Cárdenas-Barrón, L.E. 2016. Pricing and lot sizing for an EPQ inventory model with rework and multiple shipments. TOP, 24: 143-155.

Wang, K. \& Tung, C.T. 2011. Construction of a model towards EOQ and pricing strategy for gradually obsolete products. Applied Mathematics and Computation, 217: 6926-6933.

Wee, H.M., 1993. Economic production lot size model for deteriorating items with partial back-ordering. Computers and Industrial Engineering, 24: 449-458.

Yang, P.C. 2004. Pricing strategy for deteriorating items using quantity discount when demand is price sensitive. European Journal of Operational Research, 157(2):389-97.

Zhang, J., Wang, Y., Lu, L. \& Tang, W. 2015. Optimal dynamic pricing and replenishment cycle for non-instantaneous deterioration items with inventory-level-dependent demand. International Journal of Production Economics, 170: 136-145. 